\title{
California grape phylloxera more variable than expected
}

\author{
Jeffrey Granett $\square \quad$ Andrew Walker $\square \quad$ John De Benedictis \\ Genine Fong $\square$ Hong Lin $\sqcup$ Ed Weber
}

phylloxera's biology, its life cycle and how grape species and rootstocks resist its feeding.

This paper reviews our recent discoveries that the DNA and feeding behavior of different collections of California phylloxera are relatively diverse. The discovery of diversity in biological populations is not novel, but the amount we found in California was unexpected. Because phylloxera were supposedly introduced into California a relatively short time ago, and they only reproduce asexually on the roots, we expected a relatively low level of diversity.

The variability in phylloxera's ability to feed on different grape species and cultivars is of central importance to the use of rootstocks. Vitis species and the rootstocks bred from them are not uniformly resistant to grape phylloxera, nor are grape phylloxera types uniformly aggressive on a given species or rootstock. As is common throughout biology, there is variability in both the plant and the insect. Many questions have emerged: What generated the diversity? Are other rootstocks in imminent danger from a damaging biotype? How does this diversity affect the breeding and selection of new rootstocks?

To begin addressing these questions, we describe experiments to evaluate the variability of grape phylloxera in California and elsewhere. We also review what is known about phylloxera aggressiveness from other viticultural regions.

\section{Phylloxera native to the Americas}

Grape phylloxera are native to the Americas, where Vitis species serve as hosts. These American Vitis species have coevolved with phylloxera and

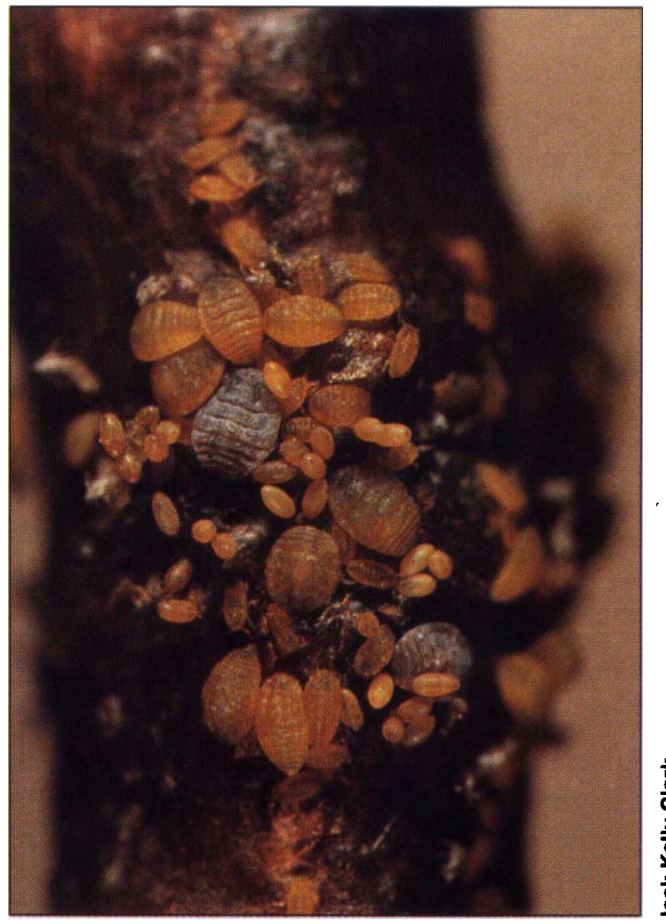

Grape phylloxera on rootstock. The minute aphidlike insects feed on the root, causing a gall to form. The expanding and cracking gall limits the root's ability to take up water and nutrients and allows rot organisms to invade.

are rarely damaged by its feeding. Other Vitis species, from parts of the world where phylloxera are not native, did not evolve this resistance and are highly susceptible to damage. Vitis vinifera, the European grape species from which most of our cultivated grapes are derived, is one such susceptible species.

Phylloxera were unintentionally imported to Europe in the mid-1800s. Vineyards before and during this period were planted on their own roots, and phylloxera soon decimated them. Numerous insecticides and other control measures were attempted, but none proved effective at limiting phylloxera's rapid spread. By the 1870 s, French viticulturists observed that the American grape species were not susceptible to phylloxera. Planchon and Laliman developed the idea that these root systems could be grafted with $V$. vinifera scion cultivars to produce a perfect plant - one whose root system was resistant to phylloxera, but whose top produced commercially desirable grapes. Breeders were soon crossing American Vitis species to produce rootstocks with phylloxera resistance, good horticultural characters (such as rooting and

about 110 years. Despite this long history, many questions remain about 
grafting ability) and adaptation to European soils and climates. Hundreds of rootstocks were produced, tested and deployed throughout Europe. As phylloxera was spread to the rest of the viticultural world, these rootstocks followed in the insect's devastating wake and are still effectively used today.

AxR\#1 was one such rootstock developed in the late 1800 s. It is a hybrid between the $V$. vinifera cultivar

Aramon and the resistant grape species $V$. rupestris. This combination was made to produce a rootstock with excellent drought and lime tolerance, the easy propagation of $V$. vinifera and the phylloxera resistance of $V$. rupestris. AxR\#1 was used in Europe and South Africa after its release, but its $V$. vinifera parentage caused it to succumb to phylloxera after 10 to 30 years of use.

Phylloxera was first found in California in the $1860 \mathrm{~s}$, and viticulturists here used the European rootstocks to combat the pest. Rootstock trials were initiated in 1905 to determine which rootstocks were best suited to

California's grape-growing regions. By 1958 the collected data were used to recommend AxR\#1 as well adapted to most of California's vineyard soils, climate, water conditions and scions.

Based on this recommendation, AxR\#1 was used in 60 to $70 \%$ of the Napa and Sonoma County plantings that occurred in the 1960-1980 planting boom.

However, AxR\#1 began to collapse under phylloxera pressure in 1983, and by 1989 it was clear that AxR\#1 was not adequately resistant to California phylloxera (see California Agriculture March-April 1991). The decline of AxR\#1 was attributed to a new type of phylloxera, designated biotype B to distinguish it from phylloxera incapable of killing AxR\#1, termed biotype A.

Biotype B has been found throughout Napa and Sonoma counties and in Lake, Mendocino, San Joaquin, Sacramento, Santa Clara and Alameda counties. By the end of 1995, over 12,000 acres of vineyards in Napa and Sonoma counties had already been removed as a direct result of biotype B phylloxera (fig. 1). Grape growers are

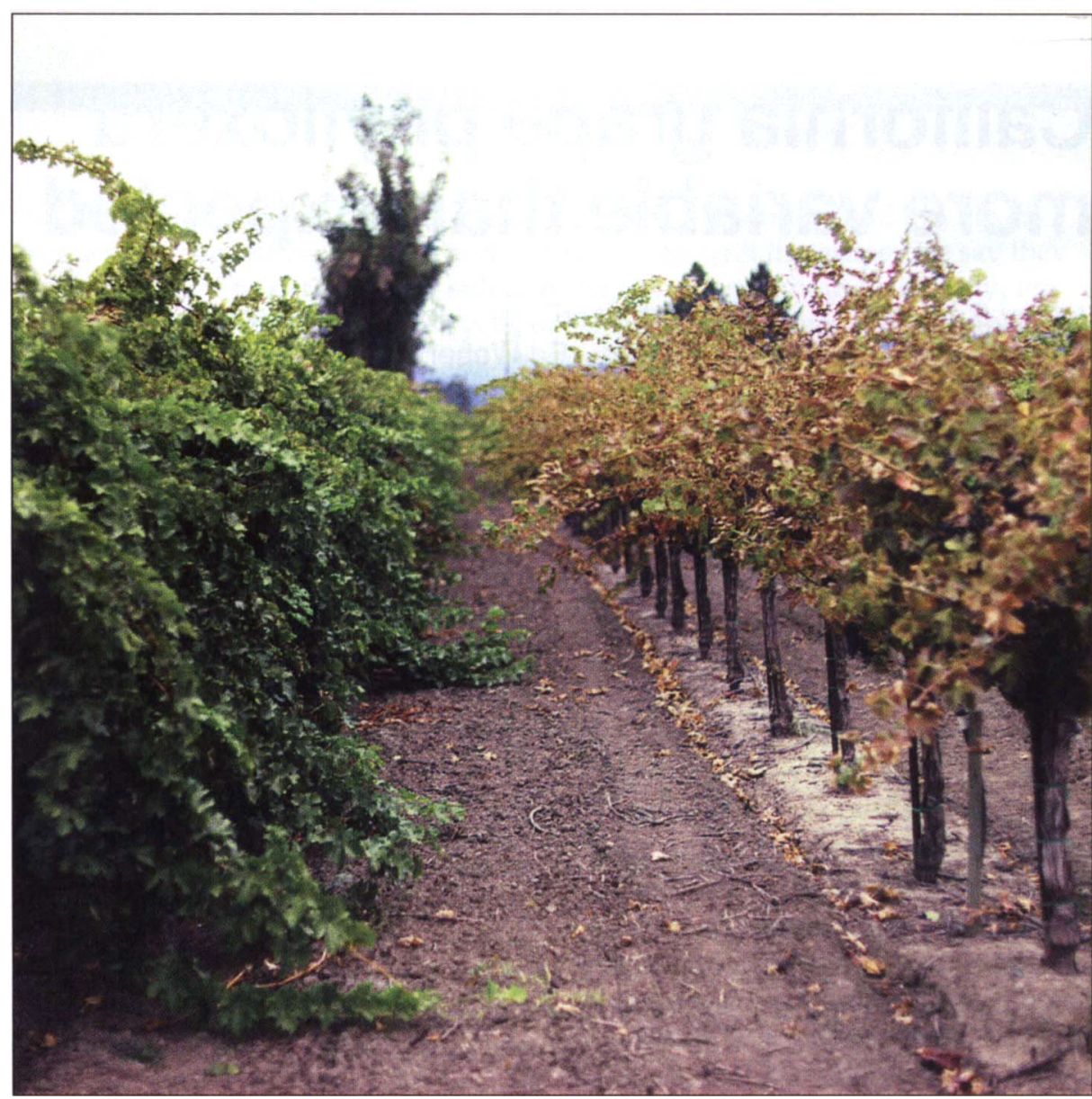

Vines on the left are grafted to the rootstock 110R, which is resistant to phylloxera biotype B. Vines on the right are grafted to AxR\#1.

replanting this acreage using rootstocks more resistant to phylloxera than AxR\#1.

\section{Phylloxera biotypes and diversity}

Biotype B phylloxera were studied by comparing their survival and reproduction to those of the less aggressive biotype A in laboratory-based assays (bioassays) using root pieces of AxR\#1 and Cabernet Sauvignon (see California Agriculture Jan-Feb 1987). The two biotypes were defined by their performance in these bioassays: biotype A phylloxera are able to grow and reproduce well on $V$. vinifera roots, but do not perform well on AxR\#1. In contrast, biotype B phylloxera are able to grow and reproduce well on both root types. In all cases, phylloxera evaluated from declining AxR\#1 vineyards have been biotype $B$ Neither biotype A nor B is able to grow well on rootstocks such as Harmony, 5C, 3309, St. George, 110R and many others. Thus biotypes are func- tional designations based on the behavior of phylloxera, not necessarily on genetic differences.

In addition to biotypes $A$ and $B$, other types of phylloxera have been found on rootstocks other than AxR\#1. Some of these phylloxera developed relatively high populations, but did not appear to affect the vines. These phylloxera behave differently than biotypes $\mathrm{A}$ and $\mathrm{B}$ in the root bioassays.

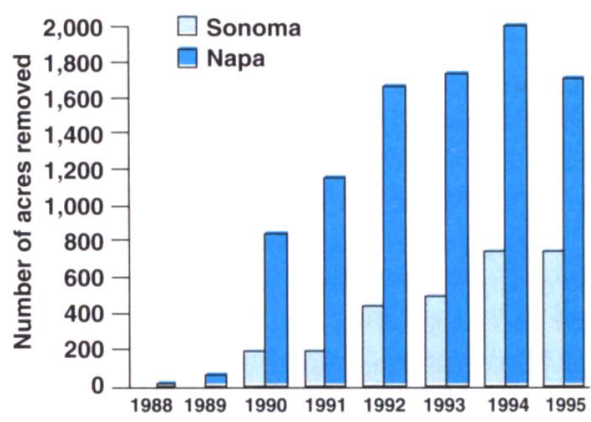

Fig. 1. Yearly total of AxR\#1 vineyard acreage removed due to biotype $B$ phylloxera infestation, Napa and Sonoma counties. 


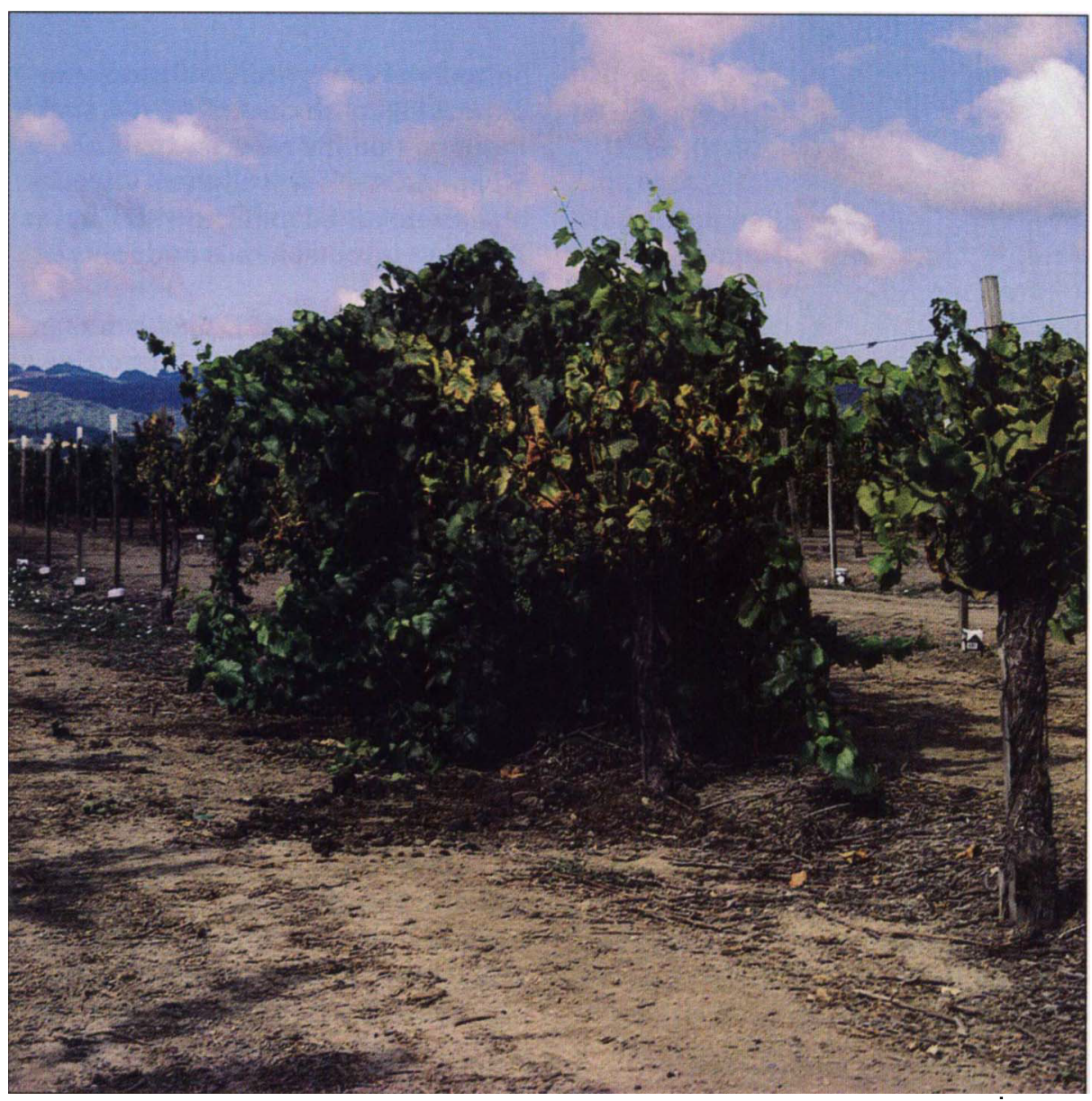

Most of the vines in this vineyard are grafted to AxR\#1. The healthy vine in the center is grafted onto St. George, a rootstock that is resistant to biotype B.

Because they were not killing their host rootstocks, but instead appeared to have adapted to them, the new phylloxera types were designated as "strains" in order to separate them from destructive biotypes.

We have recently examined the DNA of these various phylloxera types and determined that there is considerable diversity within and among the designations used to represent feeding behavior.

\section{DNA analysis of phylloxera}

Phylloxera colonies were collected from throughout California. Initially we collected phylloxera only from vineyards planted on AxR\#1 or their own roots. Bioassay results from these collections suggested that we were missing a large proportion of the insect's variability, so we expanded our collections to rootstocks other than AxR\#1. Phylloxera from other states and countries, collected by various colleagues, were also examined.
Phylloxera development was examined in petri dishes by placing single eggs onto cleaned root pieces (about .25 inch by 2 inches) of Cabernet Sauvignon, or onto roots of the rootstock the phylloxera were collected from. Insect development and reproduction was monitored under controlled conditions. Comparisons of collected colonies were based on differences in the percentage survival of phylloxera to the adult stage; the time required for individuals to reach the adult stage; and, once adults, their rate of egg laying. This information was combined to produce an egg multiplication index (EMI). This index gives a measure of how many phylloxera will be present in the next generation, and therefore estimates a given colony's ability to damage a host. EMI values have been calculated for many phylloxera colonies on a variety of rootstocks. Phylloxera survival on callus or newly formed roots was not entered into the EMI formula, because feeding on mature roots is most damaging in the field.

DNA was extracted from 13 of our lab-based phylloxera colonies representing biotypes $A$ and $B$ and several strains. Extractions were made from 200 to 300 phylloxera eggs per colony, which were surface sterilized and subjected to PCR-RAPD reactions (polymerase chain reaction-randomly amplified polymorphic DNA). RAPDs depend on the ability of randomly generated 10-base-pair DNA sequences (primers) to match with the corresponding sequences in the phylloxera DNA. The lengths of DNA between attachment locations for the primers are spliced out and replicated many times. RAPD results are viewed on agarose gels as bands of differentsized DNA, the smaller bands moving further in the gel (fig. 2). Bands are quantified by their position and their presence or absence at each possible location. When analyzed, the results estimate how closely related (or unrelated) the phylloxera DNAs are to each other (Fong et al. 1995).

RAPD analyses using 10 different primers were run three times on the 13 DNA samples to ensure reaction reproducibility. Clear RAPD bands from the three replicates were then scored as either present or absent and compared. There was no amplification of negative controls consisting of all RAPD ingredients minus phylloxera DNA.

\section{Genetic diversity within biotypes}

Table 1 shows some of the biotypes and strains we have found to date. The term "strain" has been used to designate colonies that do not respond in the same manner as biotypes $\mathrm{A}$ and $\mathrm{B}$. We are now using this term more precisely to designate genetically uniform colonies derived from a single egg; thus there can be several strains of biotype A or B based on geographic origin, differences in bioassay data or RAPD data.

Our discovery of multiple strains of genetically different biotype B phylloxera suggests that biotype $B$ has been selected for in $A x R \# 1$ vineyards more than once. There is sufficient variability, due either to multiple im- 


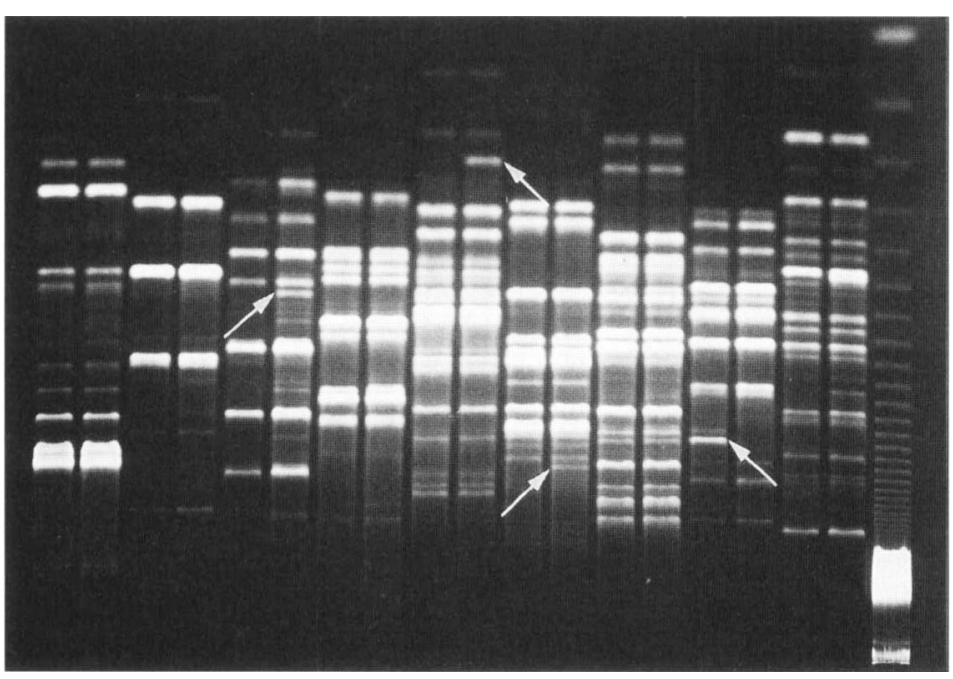

Fig. 2. Agarose gel electrophoresis of RAPD products from paired comparisons of biotype A vs. biotype B from Rutherford using 9 Operon primers. The lane on the far left is a 123 bp DNA molecular ladder; Lanes 1 and $2=$ OPG3, Lanes 3 and $4=$ OPG4, Lanes 5 and $6=$ OPG10, Lanes 7 and $8=$ OPA4, Lanes 9 and $10=$ OPA9, Lanes 11 and $12=$ OPA10, Lanes 13 and $14=$ OPA11, Lanes 15 and $16=$ OPA12 and Lanes 17 and $18=$ OPB1. Differences between the two biotypes are indicated with arrows.

portations or to rapid evolution, to suggest that phylloxera will continue to adapt to weakly resistant rootstocks. Thus a phylloxera quarantine designed to prevent the spread of aggressive strains into an AxR\#1, or other $V$. vinifera-containing rootstock vineyard, will not prevent damage for long. Local quarantines in nonphylloxerated areas of the state may still be useful because natural spread is slow. However, because natural and inadvertent spread is possible, planting of phylloxera-susceptible rootstocks in soils capable of supporting phylloxera is not recommended.

Strain 1 was isolated from Freedom growing in an Oakville rootstock trial. The vines were not declining, but this strain has survived and reproduced on young roots and callus of 5C, St. George, Dog Ridge, 101-14Mgt, Harmony and Freedom in laboratory bioassays. Strain 2 was isolated from St. George in Healdsburg and has survived and reproduced on callus and young roots of $5 \mathrm{C}$ and 101$14 \mathrm{Mgt}$. Once again, the vines from which Strain 2 was isolated were not declining. Strain 3 was isolated from Dog Ridge in Lodi. The vines were declining, but it is likely that scion root- ing was supporting the phylloxera. These three strains developed on both Cabernet Sauvignon and AxR\#1 in root bioassays and had higher EMI values than biotype $A$ on AxR\#1. They are also distinguished by their ability to maintain themselves on several non-vinifera rootstocks by feeding on callus and immature roots. This sort of feeding is not indicated in EMI values, which are based on growth and reproduction on lignified 1-yearold roots. Strain 4 was found on severely declining Harmony vines in an Oakville rootstock trial (18 vines in one replicate of the experiment). Because of strain 4's ability to damage Harmony, it has been designated as a biotype.

An apparently native strain of phylloxera has been found on $V$. girdiana in Death Valley. These phylloxera have only been found on leaves, and we have not been able to establish them on any roots. Thus they are quite different from the other phylloxera strains we have tested. We have not yet compared Death Valley phylloxera DNA with that from other strains.

Phylloxera tested from other states, including Florida, Kansas, Missouri, New York and Oregon, have been type A, but their RAPD patterns are very different from those of Californian phylloxera.

We also tested German phylloxera collected from declining vineyards planted on the rootstocks $5 \mathrm{C}, 5 \mathrm{BB}$ and 125AA (all $V$. berlandier $\mathrm{X} V$. riparia rootstocks). Although new, more aggressive phylloxera have been associated with decline, the soils are shallow and rocky and the vines have been water stressed. As expected, RAPD tests found this strain to be very different from all tested Californian strains, and it performed differently in bioassay tests. This strain was slow to establish on roots of Cabernet Sauvignon, and did not establish on AxR\#1; it was able to survive on the roots and callus of 5C and SO4. How well these German phylloxera are adapting to $V$. berlandieri $X V$. riparia rootstocks is under investigation.

We first used RAPD analysis in an effort to "fingerprint" biotypes. However, we found that strains within biotypes were genetically different. For example, RAPD patterns of the biotype A colonies listed in table 1 ranged from very similar to very distinct. This was expected, but RAPD results of the biotype $B$ colonies in table 1 , and other $B$ types we have tested, indicate that they are similarly diverse. The level of genetic diversity found among phylloxera colonies was relatively high, considering that Californian phylloxera are supposed to have been introduced 130 years ago and that they are asexual. This level of diversity was not expected, and has prompted investigations into the roles that multiple introductions, sexual recombination and mutation may have on phylloxera variability.

\section{American Vitis resistance}

The origin of grape phylloxera variability is unknown, but there are possible explanations. The variability could reflect the initial mix of populations brought to California as hitchhiking insects on infested Concord grapes and rootstocks brought with settlers from the eastern United States, and on $V$. vinifera vines from Europe. It is also possible that an unobserved sexual phase of the Californian phylloxera's life cycle may be generating variability and allowing the insects to rapidly adapt to new hosts. Some aphids are able to rapidly adapt to new hosts or to develop resistance to pesticides by altering their genetic makeup during asexual reproduction. This may also occur with the phylloxera root aphid. The variability we are observing could also reflect relatively high mutation rates, although such rates have not been observed in related insects.

The resulting variability allows new phylloxera strains to evolve as they adapt to various rootstocks. In California vineyards we have observed decline due to phylloxera only on 
rootstocks with $V$. vinifera parentage, but we have observed strains that appear to be better adapted to rootstocks with pure American Vitis species parentage. It is possible that these newly adaptive strains could become damaging biotypes.

Phylloxera biotypes have evolved in California, and anything that increases the genetic variability in a population increases the potential for selection of new biotypes. Therefore, keeping field populations low decreases the potential for selecting biotypes. Phylloxera populations can be reduced by fumigating vineyard ground prior to replanting with grapes; removing the majority of grape roots before replanting; leaving the site fallow from at least fall to late spring; and replanting using rootstocks with the highest levels of phylloxera resistance.

A survey of the world rootstock literature suggests that only rootstocks that have partial vinifera parentage are susceptible to phylloxera. AxR\#1 is half vinifera and has failed to resist phylloxera in many countries. We have also seen failure in Harmony, a rootstock with a small percentage of vinifera parentage. It is not understood how the American Vitis species resist phylloxera, but rootstocks produced with only American Vitis species have been effective against phylloxera for over 100 years. Thus it is prudent to recommend that only rootstocks with American Vitis species parentage be depended upon for phylloxera resistance.

There are anomalies to this recommendation. Like AxR\#1, 1202C is half vinifera, yet it has performed well in root bioassays and no confirmed cases of field decline have been reported in California (although it has declined in Europe). O39-16 and O43-43 have very similar parentages $(V$. vinifera $X$ Muscadinia rotundifolia), yet $\mathrm{O} 39-16$ has exhibited very high resistance in root bioassays, while O43-43 appears susceptible. We have found O43-43 declining due to phylloxera, but there are no reports of O39-16 declining.

\begin{tabular}{|c|c|c|c|c|}
\hline \multirow[b]{2}{*}{ Colony } & \multirow[b]{2}{*}{ Origin } & \multicolumn{2}{|c|}{ EMI values on } & \multirow[b]{2}{*}{$\begin{array}{l}\text { Significant responses on } \\
\text { other rootstocks }\end{array}$} \\
\hline & & $\begin{array}{l}\text { Cabernet } \\
\text { Sauvignon }\end{array}$ & AxR\#1 & \\
\hline \multirow[t]{5}{*}{ Biotype A } & Rutherford & ++ & - & - \\
\hline & Lodi & ++ & - & - \\
\hline & Fresno & ++ & - & - \\
\hline & Oregon & ++ & - & - \\
\hline & British Columbia & ++ & - & - \\
\hline \multirow[t]{3}{*}{ Biotype B } & Rutherford & ++ & ++ & - \\
\hline & Gilroy & ++ & ++ & - \\
\hline & Healdsburg & ++ & ++ & - \\
\hline $\begin{array}{l}\text { Strain } 1 \\
\text { Freedom }\end{array}$ & Oakville & + & + & $\begin{array}{l}\text { No sign of phylloxera decline in the field. However, } \\
\text { bioassays found survival and reproduction on } 5 \mathrm{C} \text {, St. } \\
\text { George, Dog Ridge, } 101-14 \mathrm{Mgt}, 44-53 \text { Malegue, } \\
\text { Harmony, and Freedom.* }\end{array}$ \\
\hline $\begin{array}{l}\text { Strain } 2 \\
\text { St. George }\end{array}$ & Healdsburg & + & + & $\begin{array}{l}\text { No sign of phylloxera decline in the field. However, } \\
\text { bioassays found survival and reproduction on } 5 \mathrm{C} \text { and } \\
101-14 \mathrm{Mgt.*}\end{array}$ \\
\hline $\begin{array}{l}\text { Strain } 3 \\
\text { Dog Ridge }\end{array}$ & Lodi & + & + & No sign of phylloxera decline in the field \\
\hline $\begin{array}{l}\text { Strain } 4 \\
\text { Harmony }\end{array}$ & Oakville & + & - & Killing Harmony in the field. \\
\hline V. girdiana & Death Valley & 0 & 0 & Unable to establish on the roots of vinifera \\
\hline German 5C & Germany & + & - & $\begin{array}{l}\text { Short-term survival and reproduction on } 5 \mathrm{C} \text { and } \\
\text { SO4.* }\end{array}$ \\
\hline
\end{tabular}

Harmony and Freedom have similar parentages, which include a small percentage of vinifera. Harmony has been susceptible in root bioassays, and we have observed decline due to phylloxera in the field, yet Freedom exhibits resistance in root bioassays, and no cases of vineyard decline have been reported. In each of these cases, one of the paired rootstocks has declined in California while the other has not. Given that we know little about phylloxera resistance, and that phylloxera are variable and adapting to new hosts, 1202C, O39-16 and Freedom cannot be recommended solely on the basis of their phylloxera resistance.

Finally, our data on strains 1, 2, 3 and 4 , and the German discoveries suggesting phylloxera damage in nonvinifera rootstocks, indicate that phylloxera susceptibility may exist in pure American species rootstocks. If so, the stability of these rootstocks may not be eternal, and we should be prepared for phylloxera strains that are better adapted and potentially damaging in the future. The way to combat this threat is through knowledge of phylloxera biology and its interactions with Vitis. Then we can predict how potentially damaging phylloxera may become and better guide the breeding of new resistant rootstocks.

J. Granett and J. De Benedictis are Entomologists, Department of Entomology, UC Davis; A. Walker is Breeder/Geneticist and Viticulturist, G. Fong is Graduate Student, and H. Lin is Postgraduate Researcher, Department of Viticulture and Enology, UC Davis; and E. Weber is Viticulture Farm Advisor, UC Cooperative Extension, Napa County.

We wish to thank the American Vineyard Foundation, the California Table Grape Commission, The Wine Group, Inc. and the California Grapevine Rootstock Improvement Commission for funding this project. We also gratefully acknowledge funding from a specific cooperative agreement with the USDA/ARS-Fresno for phylloxera research.

\section{For further reading:}

Fong, G., Walker, M.A. and Granett, J. 1995. RAPD assessment of California phylloxera diversity. Molecular Ecology 4:459-464.) 